\title{
IEDITORIAL
}

\section{Cardioverter-defibrillator in children and young patients with congenital heart disease. Time to define ICD selection}

\author{
Massimo S. Silvetti \\ Paediatric Cardiology and Cardiac Arrhythmia / Syncope Unit, Bambino Gesù Children's Hospital and Research Institute, Rome, Italy
}

RELATED ARTICLE

by Lewandowski et al, see p. 869

Correspondence to:

Massimo S. Silvetti, MD, Cardiac Arrhythmias / Syncope Unit, Department of Paediatric Cardiology and Cardiac Surgery, Bambino Gesù Children's Hospital and Research Institute, Via Torre di Palidoro 1, 00050 Palidoro-Fiumicino, Rome, Italy, phone: +390668593354, email: mstefano.silvetti@opbg.net Received: August 13, 2020. Accepted: August 14, 2020. Published online: September 25, 2020. Kardiol Pol. 2020; 78 (9): 839-841 doi:10.33963/KP.15620 Copyright by the Author(s), 2020
The use of implantable cardiac defibrillators (ICDs) to prevent sudden cardiac death from malignant ventricular arrhythmias in children is increasing. However, factors related to children (body dimensions, growth, complex anatomy, physical activity) and devices (size, lead characteristics) affect the use of ICD and may cause complications. ${ }^{1}$

Four main systems of ICD have been developed: 1) Transvenous systems are the typical ICD type of adult patients, involving a subclavear device position and transvenous defibrillation lead, usually implanted in the subpulmonary ventricle ${ }^{1}$; 2) Epicardial systems require epicardial leads for pacing/sensing and epicardial defibrillation patches The device is placed in an abdominal pocket. ${ }^{2}$ They were the first systems implanted and are now obsolete; 3) Epicardial systems and defibrillation coils have replaced the epicardial patches with defibrillation array/coils implanted in the subcutaneous tissue, ${ }^{3,4}$ pericardial or pleural space $\left.{ }^{5,6} ; 4\right)$ The entirely subcutaneous system (S-ICD) is the most recent option in this field. ${ }^{7,8}$

Despite recent technical progress, pacing leads remain the "weakest link" of the system, particularly in growing patients. ${ }^{9}$ As a general rule, the fewer leads are implanted, the fewer complications will occur. ${ }^{9}$ The most frequent complications that pediatric ICD implanters encounter are lead malfunctions, followed by inappropriate shocks, infections and vascular or valvular complications. Moreover, what is technically feasible, does not necessarily have to be done. A physician relatively unexperienced in the management of all the possible complications that might occur during follow-up, but with good technical skills can certainly perform a dual/3-chamber ICD implantation in small children. However, the knowledge of the long-term outcome of pacing systems may guide the experienced operators to use a more conservative approach. In fact, a simpler system could be implanted early in childhood, preventing this way significant complications over the follow-up period without impairing cardiac physiology and system efficacy. Then, a more physiological system can be implanted after puberty. In this setting, studies reporting long-term results are welcome and may help accumulate evidence in order to delineate more appropriate indications. Lewandowski et $\mathrm{al}^{10}$ in this issue of Kardiologia Polska (Kardiol Pol, Polish Heart Journal) reported their 22-year single-center experience in a large cohort of pediatric patients. The group mainly included patients with cardiomyopathies and heart rhythm and conduction disorders, mostly implanted with transvenous systems, rarely with S-ICD. Their results in terms of appropriate (26\%) and inappropriate (31\%) therapies were consistent with published data. 1,2,5, $6,11,12$ Other complications were surprisingly rare. Only infections (6\%) and one case of severe tricuspid regurgitation were system-related. A multicenter registry of transvenous ICD in pediatric and congenital heart disease patients showed early complications in $12 \%$ of patients (namely: lead placement issues, infections, bleeding and vascular disorders). ${ }^{1}$ The same registry also reported chronic complications (lead malfunction/dislodgement, infections, electrical storm, inappropriate shocks) in $26 \%$ of patients. ${ }^{1}$ Young patients are particularly at risk of infections and lead complications ${ }^{13}$ and survive 
longer than their ICD leads. Transvenous leads may dislodge, stretch, fracture, show insulation breaches, either acutely or chronically. Physical activity and growth of the children treated are major causes of those complications. Conversely, epicardial systems show even worse results than transvenous ones: in addition to the risk of strangulation, pacing/sensing leads have high risk of fracture, due to body's growth and to external forces that impose greater demands on the leads by flexion-extension and lateral thoraco-abdominal movements. ${ }^{6,14}$ Abdominal defibrillator cans and subcutaneous coils could also migrate because of somatic growth and could change the electrical field not ensuring a correct defibrillation. However, changes in the implantation technique of epicardial systems, with pleural shock coils and the devices placed in a subcardiac, extrapericardial location, decreased the revision rate. ${ }^{6}$

A possible explanation for the favorable outcome reported in the study by Lewandowski et $\mathrm{al}^{10}$ could be the high number of single-chamber devices. This simpler approach, as underlined above, decreases the number of leads and the bulk of the device pocket, and therefore lowers the risks of vascular occlusion, system erosion/infection, lead adherence, malfunction and dislodgement.

Lewandowski et $\mathrm{al}^{10}$ reported also 6 deaths, representing a $7.5 \%$ mortality rate. However, as few as 2 cases have to be ascribed to lead malfunction, whereas in the other patients the cause of death was heart failure or it was unknown. In other pediatric studies with a relatively comparable long-term follow-up, the mortality rate ranged from 3 to $5 \%, 1,11,12,15$ and was rarely caused by ICD failure.

Implanting an entirely subcutaneous defibrillator is an attractive option that offers many advantages in growing patients. The absence of transvenous components in the system reduces operative risks (pneumothorax, hemothorax, cardiac perforation) and main lead/lead-extraction complications, risks of endocarditis or sepsis, along with preserving venous patency and the appropriate function of the tricuspid valve. Strong indications for S-ICD implantation are: young age, primary prevention, poor vascular access, previous system infection or elevated infection risk. Contraindications are as follows: need for antitachycardia pacing, and above all, pacing indications and failed screening. The rate of pediatric patients eligible for the screening test for S-ICD is around $80 \% .^{8}$ Although the rate of inappropriate shocks, following the device technical evolution has been reduced from $25 \%$ to $7 \%,{ }^{15,7,8}$ the main limitation of S-ICDs in young patients is their large size as compared with standard ICDs. The majority of surgical complications requiring revision described so far involved skin erosions. ${ }^{8,15}$
Learning curve and implantation technique may also play a role. As a matter of fact, the 3 -incision technique and subcutaneous pocket have higher risk than the 2-incision and intermuscular pocket. Moreover, patients with body mass index $(\mathrm{BMI})<20 \mathrm{~kg} / \mathrm{m}^{2}$ are at higher risk of complications. ${ }^{8}$

In conclusion, the ICD selection in young patients should follow the suggestions presented below:

1 Infants and small children: the preferred choice is the implantation of an epicardial ICD system with either subcutaneous, pericardial or pleural shock coils.

2 Children weighing more than $30 \mathrm{~kg}$ : a transvenous single lead, a single coil ICD, is the preferred choice. Dual chamber ICDs, unless absolutely necessary, may be postponed after puberty. 3 In patients with a BMI $>20 \mathrm{~kg} / \mathrm{m}^{2}$, S-ICD should be the preferred choice, unless contraindicated.

What in the future? Leadless pacemakers added to a "smaller" S-ICD will be probably the best option.

\section{ARTICLE INFORMATION}

DISCLAIMER The opinions expressed by the author are not necessarily those of the journal editors, Polish Cardiac Society, or publisher.

\section{CONFLICT OF INTEREST None declared.}

OPEN ACCESS This is an Open Access article distributed under the terms of the Creative Commons Attribution-NonCommercial-NoDerivatives $4.0 \mathrm{In}$ ternational License (CC BY-NC-ND 4.0), allowing third parties to download articles and share them with others, provided the original work is properly cited, not changed in any way, distributed under the same license, and used for noncommercial purposes only. For commercial use, please contact the journal office at kardiologiapolska@ptkardio.pl.

HOW TO CITE Silvetti MS. Cardioverter-defibrillator in children and young patients with congenital heart disease. Time to define ICD selection. Kardiol Pol. 2020; 78: 839-841. doi:10.33963/KP.15620

\section{REFERENCES}

1 Berul CI, Van Hare GF, Kertesz NJ, et al. Results of a multicenter retrospective implantable cardioverter-defibrillator registry of pediatric and congenital heart disease patients. J Am Coll Cardiol. 2008; 51: 1685-1691.

2 Korte T, Koditz H, Niehaus M, et al. High incidence of appropriate and inappropriate ICD therapies in children and adolescents with implantable cardioverter defibrillator. PACE. 2004; 27: 924-932.

3 Berul CI, Triedman JK, Forbess J, et al. Minimally invasive cardioverter defibrillator implantation for children: an animal model and pediatric case report. PACE. 2001; 24: 1789-1794.

4 Drago F, Fazio G, Silvetti MS, et al. A successfully novel ICD implantation and medical treatment in a child with LQT syndrome and self-limiting ventricular fibrillation (letter). Int J Cardiol. 2007; 118: e108-e112.

5 Winkler F, Dave H, Weber R, et al. Long-term outcome of epicardial implantable cardioverter-defibrillator systems in children: results justify its preference in paediatric patients. Europace. 2018; 20: 1484-1490.

6 Muller MJ, Dieks JK, Backoff D, et al. Efficacy and safety of non-transvenous cardioverter defibrillators in infats and young children. J Interv Card Electrophysiol. 2019; 54: 151-159.

7 Bettin M, Larbig R, Rath B, et al. Long-term experience with the subcutaneous implantable cardioverter-defibrillator in teenagers and young adults. J Am Coll Cardiol Clin Electrophysiol. 2017; 3: 1490-1506.

8 Silvetti MS, Pazzano V, Verticelli L, et al. S-ICD: is it ready for use in children and young adults? A single-center study. Europace. 2018; 20: 1966-1973.

9 Silvetti MS, Drago F, Grutter G, et al. Twenty years of cardiac pacing in paediatric age: 515 pacemakers and 480 leads in 292 patients. Europace. 2006; 8: 530-536.

10 Lewandowski M, Syska P, Kowalik I. Children and young adults treated with transvenous and subcutaneous implantable cardioverter-defibrillators: a 22-year single-center experience and new perspectives. Kardiol Pol. 78: 869-874.

11 Frommeyer G, Feder S, Bettin M, et al. Long-term single-center experience of defibrillator therapy in children and adolescents. Int J Cardiol. 2018; 271: 105-108. 
12 Aykan HK, Karagoz T, Gulgun M, et al. Midterm results of implantable cardioverter defibrillators in children and young adults from a single center in Turkey. PACE. 2016; 39: 1225-1239.

13 Janson CM, Patel AR, Bonney WJ, et al. Implantable cardioverter-defibrillator lead failure in children and young adults: a matter of lead diameter or lead design? J Am Coll Cardiol. 2014; 63: 133-140.

14 Silvetti MS, Drago F, Di Carlo D, et al. Cardiac pacing in paediatric patients with congenital heart defects: transvenous or epicardial? Europace. 2013; 15: 1280-1286.

15 Jarman JW, Lascelles K, Wong T, et al. Clinical experience of entirely subcutaneous implantable cardioverter-defibrillators in children and adults: cause for caution. Eur Heart J. 2012; 33: 1351-1359. 